\title{
The effects of rewarder familiarity and differential reward preference on intrinsic motivation
}

\author{
KIRK M. GRIFFITH, LINDA L. DeLOACH, and RICHARD C. LaBARBA \\ University of South Florida, Tampa, Florida
}

\begin{abstract}
The effects of differentially preferred extrinsic rewards and familiarity of rewarder on subsequent intrinsic motivation for a reading task were investigated in 96 second-, third-, and fourth-grade children. The results revealed that children rewarded by a controlling familiar person spent less time with a book and read fewer words than those rewarded by an unfamiliar person, except when no reward was offered. For the controlling familiar groups, the high-preference reward condition resulted in significantly less time spent with the book than did the no-reward condition. For the unfamiliar groups, in contrast, the high-preference condition resulted in significantly more time spent with the book than did the no-reward condition. These findings are discussed within the context of cognitive evaluation theory.
\end{abstract}

Different external events, such as rewards, constraints, and feedback, can lead to an undermining of intrinsic motivation. According to cognitive evaluation theory (Deci, 1975; Deci \& Ryan, 1980), there are two functional aspects of external events: an informational aspect and a controlling aspect. When a reward is delivered to produce a given behavioral outcome, the controlling apsect is more likely to be perceived as salient, whereas a reward that conveys relevant feedback, for example, regarding competence, is more likely to be perceived as informational. When the recipient of the reward or other external event perceives the controlling aspect as more salient than the informational aspect, the external event is likely to reduce intrinsic motivation. However, when the event is perceived as more informational than controlling, and the information provided implies competence, intrinsic motivation tends to increase or at least be maintained (Deci, Schwartz, Sheinman, \& Ryan, 1981; Pittman, Davey, Alafat, Wetherill, \& Kramer, 1980; Rosenfield, Folger, \& Adelman, 1980).

According to cognitive evaluation theory, situation variables, such as reward expectancy (Lepper, Greene, \& Nisbett, 1973), contingency, (Karniol \& Ross, 1977), and reward salience (Ross, 1975), are subordinate to the functional aspects of rewards (Deci \& Ryan, 1980). That is, the effect a reward has on intrinisc motivation is more a function of the relative salience of the two functional aspects of the reward. For example, whereas a reward needs to be salient to have an effect (Ross,

This study is based on a thesis submitted to the Department of Psychology, University of South Florida, in partial fulfillment of the requirements for the master's degree. We would like to thank Sara Best and Patsy Burford for their cooperation with this study. Requests for reprints should be sent to Kirk M. Griffith, Department of Psychology, University of South Florida, Tampa, FL 33620 .
1975), a salient reward can be perceived as informational or controlling. Furthermore, competence information in the form of social comparison can mitigate the controlling aspects of contingent reward procedures and reduce the probability of producing an undermining effect (Boggiano \& Ruble, 1979).

It follows from cognitive evaluation theory that characteristics in the rewarder may well influence how rewards and other external events are perceived. However, this variable has received relatively little attention. A recent study by Deci, Nezlek, and Sheinman (1981) indicated that a rewarder's orientation toward control or autonomy affects how rewards are used in a classroom and therefore which functional aspect is more salient. Rewards administered by a teacher with a controlling orientation tend to undermine intrinsic motivation, whereas rewards administered by a teacher with an autonomy orientation tend to maintain intrinsic motivation. In a validation study of an instrument to assess adults' orientation toward control versus autonomy with children, it was found that students of autonomyoriented teachers tend to be more intrinsically motivated and have higher self-esteem than students of controllingoriented teachers (Deci et al., 1981).

Another rewarder variable of both theoretical and practical importance is the familiarity of the rewarder to the rewardee. On the basis of previous investigations of intrinsic motivation among school-age children, the effects of being rewarded by an unfamiliar adult experimenter compared with those of being rewarded by a familiar adult are not clear (McLoyd, 1979). For the purposes of this paper, familiarity is defined as one individual's having a reward history with another. That is, previous experimental investigations of the undermining effect in school children have used unfamiliar experimenters to reward subjects or to introduce other 
experimental manipulations. Given the differential effects of rewards on intrinsic motivation as a function of rewarder orientation, it is reasonable to expect that different types of relationships between a child and a rewarder might determine how rewards are perceived by the child. A child's reward history with a controlling teacher increases the likelihood of a given reward procedure involving the teacher being perceived as controlling. In contrast, the controlling versus autonomy orientation of an unfamiliar adult would be unknown. Given this, reward procedures involving the unfamiliar adult would be less systematically affected by the child's expectations or attributions regarding the rewarder. One would therefore expect a different undermining effect following a reward administered by a familiar controlling figure from that following one administered by an unfamiliar figure.

Another reason for comparing rewarder familiarity is related to ecological validity (Tunnell, 1977). Classroom rewards for engaging in academic or social activities are generally given by the teacher, not by an unfamiliar adult experimenter. Therefore, given the importance of rewarder characteristics for the perceived relative salience of the functional aspects of rewards, the present study examined the effects of rewarder familiarity and differential reward preference on intrinsic motivation for a reading task in elementary school children.

The present study was designed to examine the effects of rewarder familiarity on intrinsic motivation in the classroom. We reasoned that an unfamiliar adult rewarder would be less likely to be perceived as using the controlling aspect of rewards than would a familiar controlling teacher. Thus, we predicted that those children rewarded by a familiar rewarder would demonstrate less intrinsic motivation than those rewarded by an unfamiliar rewarder. We also predicted that a highpreference reward from a familiar rewarder would result in less intrinsic motivation than a low-preference reward or no reward. It was anticipated that these conditions would result in the perception that the activity was engaged in for external reasons rather than for intrinsic interest (Deci, 1975; Deci \& Ryan, 1980).

\section{METHOD}

\section{Design}

A 2 (familiar vs. nonfamiliar rewarder) $\times 3$ (high-preference reward vs. low-preference reward vs. no-reward condition) factorial design was used. Children were assigned randomly to each condition in an attempt to approximate an equal sex distribution of eight boys and girls in each condition.

\section{Subjects}

The subjects were 96 second-, third-, and fourth-grade children, 50 boys and 46 girls attending a local elementary school. Six classrooms, two from each grade level, were used. The children were selected from a screened subject pool; they were selected on the basis of reading ability to assure that all subjects were on grade level for reading and could, therefore, read the selected books. The school reading specialist supplied the reading-level information from school records.

\section{Experimental Activity and Materials}

The experimental activity consisted of reading from one of five storybooks chosen by the school reading specialist and experimenters. Material was selected to cover a wide range of topics and to be within the reading level of the subjects. All the storybooks were from the Sprint Library Series, a collection of books designed for use in elementary school settings, with interest and readability levels appropriate for each grade. In this manner, the subjects in each of the grade levels were given five book choices, each controlled for interest and vocabulary difficulty.

The subjects in the high- and low-preference reward conditions received one of the following: (1) a good-reader award, (2) an eraser, (3) a pencil, (4) a crayon, or (5) a plastic toy. The good-reader award was a $3 \times 5$ in. card with a star and a red ribbon attached and a space for the child's name and school. Rewards of this type have been used in previous studies on the effects of extrinsic rewards on intrinsic motivation (Lepper et al., 1973; McLoyd, 1979).

\section{Procedure}

The four experimenters, two males and two females, were introduced as visiting teachers from another school who were interested in finding out what kinds of books students found interesting. The experiment was conducted in the pod centers at the elementary school during the morning reading periods. The pod center is a centrally located, common work area shared by four adjoining classrooms.

Before the experiment began, each subject was individually brought to a table at one end of the pod center by an experimenter "teacher." For the high- and low-preference reward conditions, the experimenter followed rank-ordering procedure described by McLoyd (1979) to determine each child's most and least preferred reward. No mention of reward was made to the no-reward group. A similar ranking method was used to allow each child to select the book (on the basis of a synopsis of each of the five books) in which he/she was most interested. This reading-choice procedure was used to control for level of interest across subjects. Each child's reward and book preferences were recorded.

When each child was brought to the experimental table in the pod center for the reading task, the first-choice book was presented, and the appropriate reward was placed on the table for salience (Ross, 1975). Children in the high-preference reward condition saw their first-choice reward, and children in the lowpreference condition saw their unchosen reward. To control for reading speed, a bookmark was placed in each book to indicate about 250 words in the story. This ensured that all subjects were exposed to about the same amount of reading material.

The subjects in the high-preference reward condition were told that, by reading as far as the bookmark, they would receive their first-choice reward, whereas those in the low-preference reward group were told they would receive the unchosen reward. Depending on level of familiarity, the child's teacher or the experimenter "teacher" said, "If you read up to this bookmark, I will give you this reward. When you're finished I will give you the reward and you can tell me how much you like the book." Because they had been told the reason for reading the book was to find out what kinds of books students found interesting, the children were asked how they liked the book. This procedure was used to reduce the likelihood of children's being concerned about being evaluated.

In the no-reward condition, each child was asked to read as far as the bookmark and then to indicate how much they liked the book. For all conditions, the experimenter "teacher," "working" at another table in the pod center $5 \mathrm{~m}$ behind the child, recorded the amount of time (in seconds) each subject 
took to read the selection. After the children in the reward conditions had finished reading, their respective rewards, with the children's names written on them, were placed on a "reward board." The teacher (familiar condition) or the experimenter "teacher" (unfamiliar condition) then said, "Here is your reward for reading that part of the book. It is yours to keep and I will give it to you as soon as all the children have had a chance to read some of the books. How did you like the book?" For the no-reward conditions, the experimenter "teacher" (unfamiliar) or the child's teacher (familiar) asked, "How did you like the book?"

At this point, for all conditions, the experimenter or the child's teacher explained that they were through, got up with the child, and walked the child back to the classroom. Just before entering the classroom, the experimenter or teacher obviously looked at a clock, turned back to the pod center, and said, "Oh, it's not quite time to go back to your room yet. I have some work to do so you have some free time to do whatever you like at this table. Do whatever you want to, OK?" For the reward groups, it was explained that no additional rewards were available. The experimenter or teacher then acted busy at another table about $5 \mathrm{~m}$ behind the child. This procedure of leaving and pretending to ignore the child was used to reduce the confounding influence of giving the child attention for any particular activity (Anderson, Manoogian, \& Reznick, 1976).

The free-choice session lasted for $10 \mathrm{~min}$. In addition to the book, the experimental table had an assortment of connect-thedot and crossword-puzzle books. Several measures of subsequent activity were taken: (1) the first choice of activity, (2) the time spent reading, (3) the number of words read, and (4) a question regarding which activity the child endorsed as his/her favorite. When $10 \mathrm{~min}$ had elapsed, the experimenter or the teacher asked, "If your best friend asks what the best or most fun thing to do at the table is, what would you say?" If the child had read during the free-choice session, he/she was asked to place a bookmark where he/she had stopped. The child was then returned to the classroom. After the experiment was concluded, all children received their first-choice reward and all of the participants were debriefed.

\section{RESULTS}

Following the procedure of previous investigators (Boggiano \& Ruble, 1979; Lepper et al., 1973), a log transformation, $Y=\log$ transformation, $Y=\log (Y+1)$, on the number of seconds spent with the book and the number of words read was performed to produce homogeneity of variance (Winer, 1971). Preliminary analyses revealed that the main and interaction effects for sex of experimenter, sex of subject, and grade of subject were all nonsignificant on the intrinsic-motivation measures. Consequently, the data were pooled across these factors in the subsequent analyses. The overall mean number of seconds taken to read the 250-word selection during the experimental period was $185.46 \mathrm{sec}$. A 2 x 3 ANOVA of the transformed number of seconds revealed no significant main or interaction effects.

A $2 \times 3$ ANOVA of the transformed number of seconds spent with the book during the free period indicated a significant main effect for familiarity $[F(1,90)=$ $12.50, \mathrm{p}<.006]$ and a significant interaction of familiarity and reward value $[\mathrm{F}(2,90)=3.91, \mathrm{p}<.02]$. Children rewarded by an unfamiliar figure spent more time with the book than did children rewarded by a familiar teacher, except when no reward was given. In that instance, the means did not differ.
To test the hypothesis of this study, we calculated Fisher's least significant difference (lsd) for comparisons among the transformed unfamiliar means. An lsd of 0.72 indicates that subjects who received a highpreference reward spent more time with the book than did subjects who received no reward. In contrast, subjects who received a high-preference reward from a familiar rewarder spent less time with the book than did those receiving no reward from a familiar rewarder (1sd = 1.68). Contrary to prediction, for both levels of familiarity, there was no significant difference between subjects who received the high-preference reward and subjects who received the low-preference reward. Thus, the amount of time that subjects spent with the book in the free period varied as a function of familiarity and reward/ no reward. As predicted, the unfamiliar-rewarder groups spent more time with the book than did the familiarrewarder groups. Furthermore, the familiar-rewarder groups spent less time with the book in the high-preference condition than did the no-reward group. However, the unfamiliar-rewarder groups spent more time with the book in the high-preference condition than did the no-reward group. A $2 \times 3$ ANOVA of the transformed number of words read indicated a significant main effect for familiarity $[F(1,90)=9.48, p<.002]$, but the interaction of familiarity and reward preference was not significant $[F(2,90)=2.60, \mathrm{p}<.08]$.

Chi-square analyses of expressed preference for activity in the free period were performed based on responses to the question, "If your best friend asks what the best or most fun thing to do at the table is, what would you say?" Responses from the children in the two familiarity groups and the three reward groups did not differ. Twenty-seven (56\%) children in the unfamiliarrewarder group and $11(23 \%)$ children in the familiarrewarder group contacted the book first in the free period. A $\chi^{2}$ analysis indicated that this difference was significant $\left[\chi^{2}(1)=9.80, p<.01\right]$. There were, however, no significant differences among the three reward groups in the number of children who contacted the book first.

\section{DISCUSSION}

The results of the present study generally support our predictions for the effects of rewarder familiarity as derived from cognitive evaluation theory. As such, they provide further support for conceptualizing rewarder variables in terms of their controlling and autonomy aspects (Deci \& Ryan, 1980). In addition, the present findings provide empirical support for previous suggestions that teachers, using tangible rewards, can produce an undermining effect under certain conditions.

In the present study, children rewarded by a familiar rewarder demonstrated less intrinsic interest in reading when highpreference rewards were used than when no reward was given. These data are consistent with previous findings from studies using unfamiliar rewarders (McLoyd, 1979) and offer a more ecologically valid demonstration of the undermining effect in the classroom. There was, however, no significant difference in the effect of high- versus low-preference reward on intrinsic interest in reading. Common to both conditions was an explicit agreement that the child would receive a reward for reading a specific amount. Since there was no significant difference, a child's simply agreeing to read for the reward in both conditions 
was apparently sufficient to produce less interest than reading for no reward. Perhaps either reward was controlling enough to produce less interest than that produced in the no-reward condition. Thus, receiving a reward from a familiar, controlling figure, regardless of preference level, was sufficient to produce an undermining effect.

As predicted, the present findings suggest that, except for the no-reward group, those children who were rewarded by an unfamiliar rewarder showed more intrinsic interest in reading than those rewarded by a familiar rewarder. Familiar rewarders were probably perceived by the children as more controlling in orientation than the unfamiliar rewarders. It is reasonable to assume that the teachers, in the exercise of their normal routines and responsibilities, were seen as relatively more controlling than the experimenter "teachers," who were not identified with the school. Thus, the rewards given by the unfamiliar rewarders were possibly perceived as relatively noncontrolling regardless of value, whereas rewards given by familiar rewarders were perceived as relatively controlling.

The present data indicate that children in the high-preference reward, unfamiliar-rewarder condition showed more intrinsic motivation than those in the no-reward, unfamiliar-rewarder condition. This effect can be explained in terms of the unfamiliar rewarders' being perceived as relatively less controlling than the familiar rewarders. Autonomy-oriented teachers have been found to use rewards to maintain or enhance intrinsic motivation more than controlling-oriented teachers (Deci et al., 1981).

In summary, our results provide a more ecologically relevant demonstration of the undermining effect of some reward procedures in the classroom. In this case, controlling-oriented teachers were more likely to produce an undermining effect using rewards than when either no reward was given or when unfamiliar rewarders used rewards. These results are consistent with cognitive evaluation theory (Deci, 1975; Deci \& Ryan, 1980) conceptualization of autonomy versus controlling orientations in teachers, and suggest that further investigations of specific rewarder characteristics might be useful for understanding how teachers can affect intrinsic motivation in the classroom.

\section{REFERENCES}

Anderson, R., Manoogian, S., \& Reznick, J. (1976). Undermining and enhancing of intrinsic motivation in pre-school children. Journal of Personality and Social Psychology, 34, 915-922.
Boggiano, A. K., \& Ruble, D. N. (1979). Competence and the overjustification effect: A developmental study. Journal of Personality and Social Psychology, 37, 1462-1468.

Decı, E. L. (1975). Intrinsic motivation. New York: Plenum Press.

Deci, E. L., Nezlek, J., \& Sheinman, L. (1981). Characteristics of the rewarder and intrinsic motivation of the rewardee. Journal of Personality and Social Psychology, 40, 1-10.

Deci, E. L., \& RyAN, R. M. (1980). The empirical exploration of intrinsic motivational processes. In L. Berkowitz (Ed.), $A d$ vances in experimental social psychology (Vol. 13). New York: Academic Press.

Deci, E. L., Schwartz, A. J., Sheinman, L., \& Ryan, R. M. (1981). An instrument to assess adults' orientations toward control versus autonomy with children: Reflections on intrinsic motivation and perceived competence. Journal of Educational Psychology, 73, 642-650.

Karniol, R., \& Ross, M. (1977). The effect of performancerelevant and performance-irrelevant rewards on children's intrinsic motivation. Child Development, 48, 482-487.

Lepper, M. R., Greene, D., \& Nisbett, R. E. (1973). Undermining children's interest with extrinsic rewards: A test of the overjustification hypothesis. Journal of Personality and Social Psychology, 28, 129-137.

McLoyd, V. C. (1979). The effects of extrinsic rewards of differential value on high and low interest. Child Development, 50, 1010-1019.

Pittman, T. S., Davey, M. E., Alafat, K. A., Wetherill, K. V., \& Kramer, N. A. (1980). Informational versus controlling verbal rewards. Personality and Social Psychology Bulletin, 6, 228-233.

Rosenfield, D., Folger, R., \& Adelman, H. F. (1980). When rewards reflect competence: A qualification of the overjustification effect. Journal of Personality and Social Psychology, 39, 368-376.

Ross, M. (1975). Salience of reward and intrinsic motivation. Journal of Personality and Social Psychology, 33, 245-254.

Tunnell, G. B. (1977). Three dimensions of naturalness: An expanded definition of field research. Psychological Bulletin, 84, 426-437.

WiNer, B. J. (1971). Statistical principles in experimental design (2nd ed.). New York: McGraw-Hill.

(Revision received for publication June 28, 1984.) 